\title{
Friction and Wear Characteristics of Polymeric Composites Reinforced by Nano Particles and Impregnated with Paraffin Oil
}

\author{
M. A. Ahdy A. ${ }^{1}$, T. A. Osman ${ }^{2}$, A. M. A. Elbatch ${ }^{3}$, W. Y. Ali ${ }^{4}$
}

\begin{abstract}
A pin on disk machine is designed and constructed to experimentally measure and investigate the friction coefficient and wear rate of two groups of compounds of (PET) - CNT, and PET - CNT and paraffin oil under variable applied loads. Polymeric Composites Reinforced by Nano Particles and Impregnated with Paraffin Oil have low friction coefficients and highly resistant to wear so it is widely used in aerospace, automobiles, packing materials and in bearing applications.

The effect of both percentages of PET with CNT and PET, CNT and paraffin oil under variable loads on coefficient of friction and wear values are carefully recorded and studied.

A historical review of the available published work has shown a need for this work. This research used test specimens were prepared by casting method. The Addition of carbon Nanotubes to the polyethylene terephthalate with specified contents of Group I showed decrease in friction coefficient and wear values with increasing CNT content and applied loads.

The tested specimens of Group II were filled by 3, 5, 10 wt. \% paraffin oil introduced with the composites of PET and CNT. Applied loads of 8, 13, 18, 23, 28, $33 \mathrm{~N}$ were used during the test. The coefficient of friction was calculated by dividing the frictional forces by the applied normal load. Specimens were weighed before and after the test and the difference between the two weights represented the wear loss.

Results of conducted tests on the compound of PET and CNT and paraffin oil under the previous loads were plotted for friction coefficient as of CNT content showed decreasing trend of friction coefficient with increasing the content of paraffin oil. According to increase of the applied loads of wear rate decreased.

\footnotetext{
${ }^{1}$ BSc Modern Academy

${ }^{2}$ Mechanical Design Dep., Faculty of Engineering, Cairo University

${ }^{3}$ Mechanical Design Dep., Faculty of Engineering Material, Helwan University

${ }^{4}$ Mechanical Design Dep., Faculty of Engineering, Menia University
} 
Finally, this research proposes a good assessment of testing polymer matrix for various applications such as bearing materials and guide ways.

Keywords: Polyethylene Terephthalate, Carbon Nanotube, Paraffin Oil, Friction Coefficient, Wear

\section{Introduction}

A Composite is a material composed of two or more components or phase [1]. In fact a composite material is to offer properties in excess of both the matrix and reinforcement phases which are net possible in conventional isotropic materials (polymers, Metals, etc.) [2].

Polymers offer properties such as low density, good well ability of reinforcement and good toughness and are easy to mould to a desired Shape. Strength properties are great important by the addition of reinforcing fillers into polymer matrices.

For Micro-scale fillers, the properties are largely independent of their sizes. However, when reinforcements are of Nano scale, their size plays a vital role due to their high surface areas and aspect ratios as in case of CNT. Therefore, the present work is to prepare Nano composites using poly (ethylene Terephthalate) (PET) and carbon fillers include (CNT) [3].

(PET) is a material from polymers family and it is a semi-crystalline material so that good strength, ductility, stiffness and hardness.

Polymers used widely in applications such as polyester, fibres, printing sheets, photographic films, magnetic tape, and engineering plastics for automobiles and electronics and electrostatic devices [4, 5, 6 and 7]. Because of its low cost and high performance, (PET) is also widely used in food packaging, such as beverage bottle and frozen food trays that can be heated in microwave or conventional ovens .

(PET) resins are produced commercially from ethylene glycol (EG) and dimethyl terephthalate (DMT) or terephthalate acid (TPA). (DMT) and (TPA) are solids.

A Carbon Nanotube (CNT) is a tube - shaped material made of carbon having a diameter measuring on the Nanometre scale. NCT are unique because the bonding between atoms is very strong and the tubes can have extreme aspect ratios $[8,9$ and 10$]$.

The object of the present experimental work are two aims namely:

(1) Study the friction force of the test specimens of two groups: Group I are compound of pure PET and PET with specified percentage of CNT under fixed time and variable applied loads. The second Group II are compound of PET with three percentages of paraffin oil and PET with Specified NCT of the Same previous Percentage under the same previous time and applied loads.

(2) Study the wear value of the test specimen of Group I and Group II.

(3) Study the effect of CNT content and applied loads on friction coefficient the two groups.

(4) Study wear of the two groups as affected by CNT and applied loads and paraffin oil. 
The hexagonal carbon ring is responsible for the type of structure when oriented differently [11, 12 and 13] CNT form three structures, armchair, and zigzag and chiral, those depend on the rolling angle of graphene. Such chirality is explained by the chiral vector as shown in Figure .1 Such a naming scheme allows three types of orientation of the carbon atoms around tube circumference .
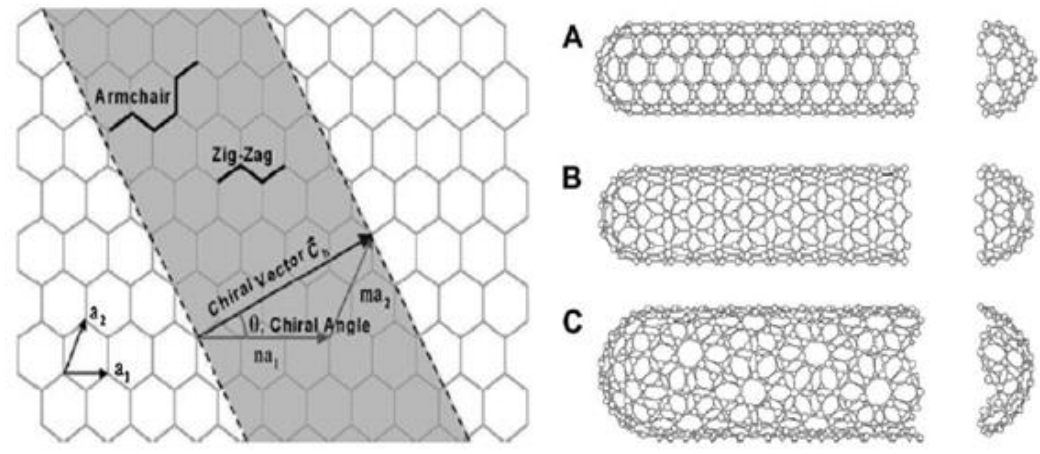

Figure 1 Schematic exhibiting how a hexagonal sheet of grapheme is rolled to develop a CNT with various chirality, as A represents the armchair, B depicts the zigzag and C shows the chiral [14].

CNT possess an excellent combination of thermal, electrical and mechanical properties which make them one of the most promising fillers to produce nanocomposites having excellent properties with low percolation thresholds for wide applications. The improvement of these properties is governed by many parameters including dispersion of the filler, interfacial interaction between the filler and the polymer, filler concentration as well as the type of polymer used [14, $15,16]$ during the last two decades, there has been an intense focus on the development of polymer/CNT nanocomposites, due to the fact that CNT have superior properties over other carbon forms such as carbon fibres and graphite. Polymer/CNT nanocomposites can be prepared by solution processing, in situ polymerization or melt processing $[17,18]$. The latter method is recommended especially for making thermoplastic matrices based nanocomposites [14].

CNT have been widely used as a filler material for composites due to superior mechanical properties [17, 19, 30, 34].

\section{Experimental Work}

\subsection{Test Rig:}

The Aim of The present investigation is to determine the friction coefficient and wear loss values of two groups of specimens at different percentages of PET, CNT and PET, CNT and paraffin oil under different applied loads over a pin of previous compounds on a rotating disk by using test rig carefully designed with the following requirements, Figure 2.

\section{Specifications:-}

- Contact configuration: pin on disk.

- Disk diameter: 190mm, 4mm thickness.

- Electric motor: 220V 1500 r.p.m, 1.5 HP.

- $\quad$ Track Radius: 25 - 90 mm

- $\quad$ Sliding Speed: up to $0.75 \mathrm{~m} / \mathrm{s}$

- Rotation Speed: 0 - $200 \mathrm{rpm}$

- Dimension of cylindrical test specimen: $8 \mathrm{~mm}$ diameter and 20mm length. 


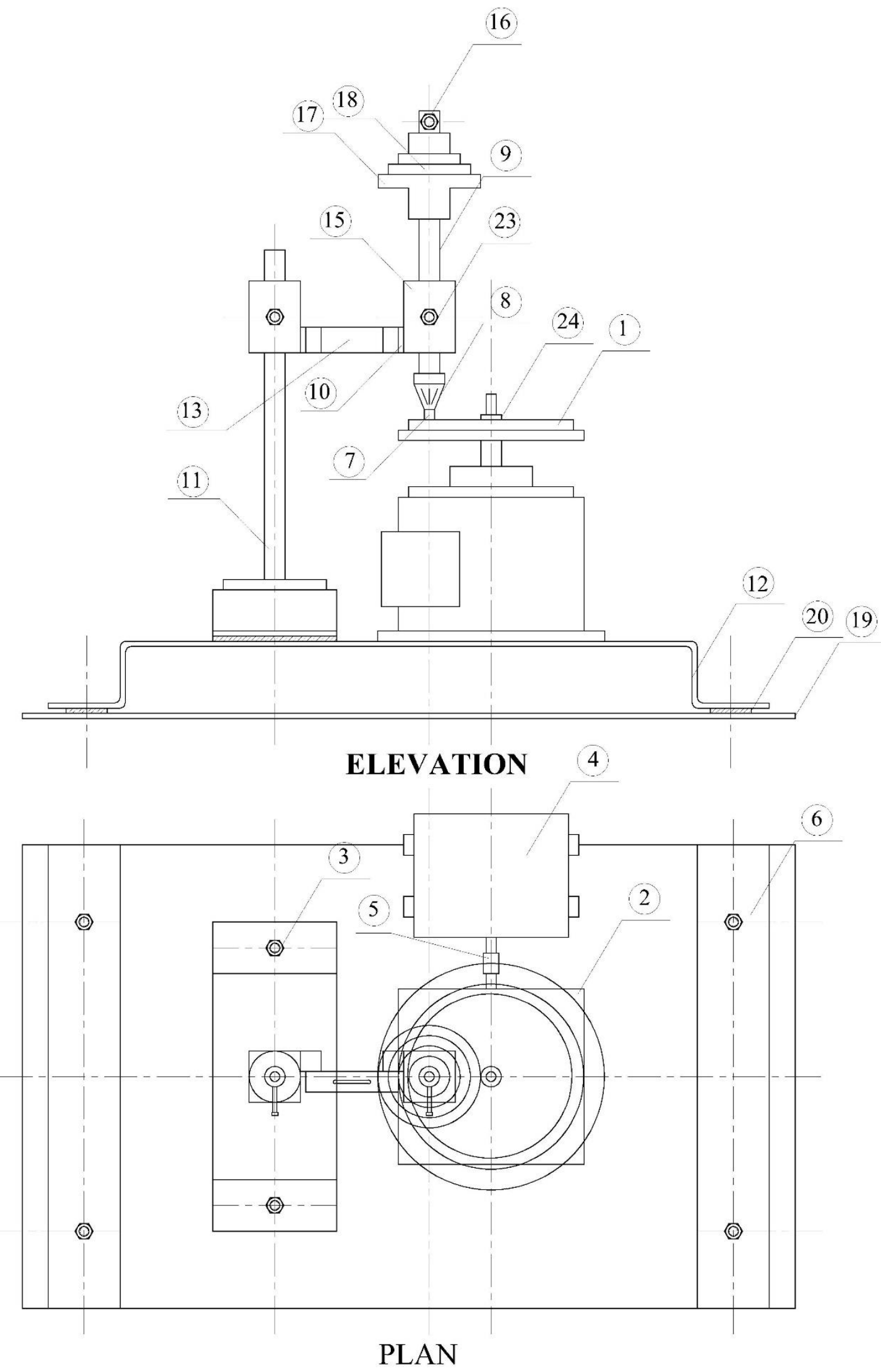

Figure 2 The Schematic Arrangement 
The test specimen (7) is mounted in chuck (8) to be vertical on the rotating disk, the chuck is mounted with vertical pin rod (9) which is fixed with an arm (10) which fixed with other vertical rod (11) fixing on small table (12). The load cell (13) is joined between the two rods by two sleeves $(15,25)$, which can be fixed by bolts (14), (16).

The loads (18) can he put on the vertical pin rod (9). The whole parts of the test rig was putting and fixed on special steel stand (19) fixed by slot through bolts (29) and rubber (20) by four bolts (21) in special slot (28).

A Test rig use test specimens of the compound of Group I and Group II as a Pin of dimension $8 \mathrm{~mm}$ diameter and $20 \mathrm{~mm}$ length and a rotating disk of diameter was constructed and expected to operative under specific applied loads.

The rig is made capable of measuring the above performance under the following conditions:

(1) Applied loads up to $32 \mathrm{~N}$.

(2) Percentage of CNT of Group I are $0.2,0.4,0.6,0.8$ and $1 \%$.

(3) Percentage of paraffin oil of Group II are 3, 5 and $10 \%$.

Experimental investigation were carried out under pure sliding condition. The design of the test rig is made in such a way as to enable further experimental work to be conducted thereon.

\subsection{Measuring Techniques:}

Some previous technique are used to measure friction forces [10, 11, 21 and 22] and wear [1, 2, 23]. A measuring technique of a load cell and special screen is used to record the friction force and special sensitive weight indicator to calculate the wear value between test specimens under various loads, Figure 3

\subsubsection{Friction Measuring:}

A direct method for measuring the friction force between the test specimen and the rotating disk could be recorded from the screen (27) provided with the load cell.

A calibration technique was carried out to give the friction force at various applied loads (18). The load cell was fixed with the arm (10) between pin rod and the vertical rod by 4 bolts (29).

\subsubsection{Wear Measurement:}

In the present work wear loss can be determined by weight the test specimen before carrying the test under applied loads and for a specified time and weight the test specimen after carrying the test and calculate the weight difference to obtain the value of wear loss happened .

\subsubsection{Mechanical Properties:}

Mechanical properties were evaluated by using universal tension test machine at the room temperature. Tensile tests were carried out with eight composites. The hardness numbers are measured using Rockwell test device (1.6 mm ball diameter). 


\subsection{Preparation of Test Specimens Composed from Two Groups:}

Before any test, the compound are prepared which composed from two groups as follows:

Group I: Polyethylene terephthalate and carbon nanotube (CNT) content.

In the thesis, casting operation is used in preparation the compound. Some researches were used extrusion technique [24, 25, 26, 27, 28]. The CNT have been added to PET with certain percentage by using conventional mixing.

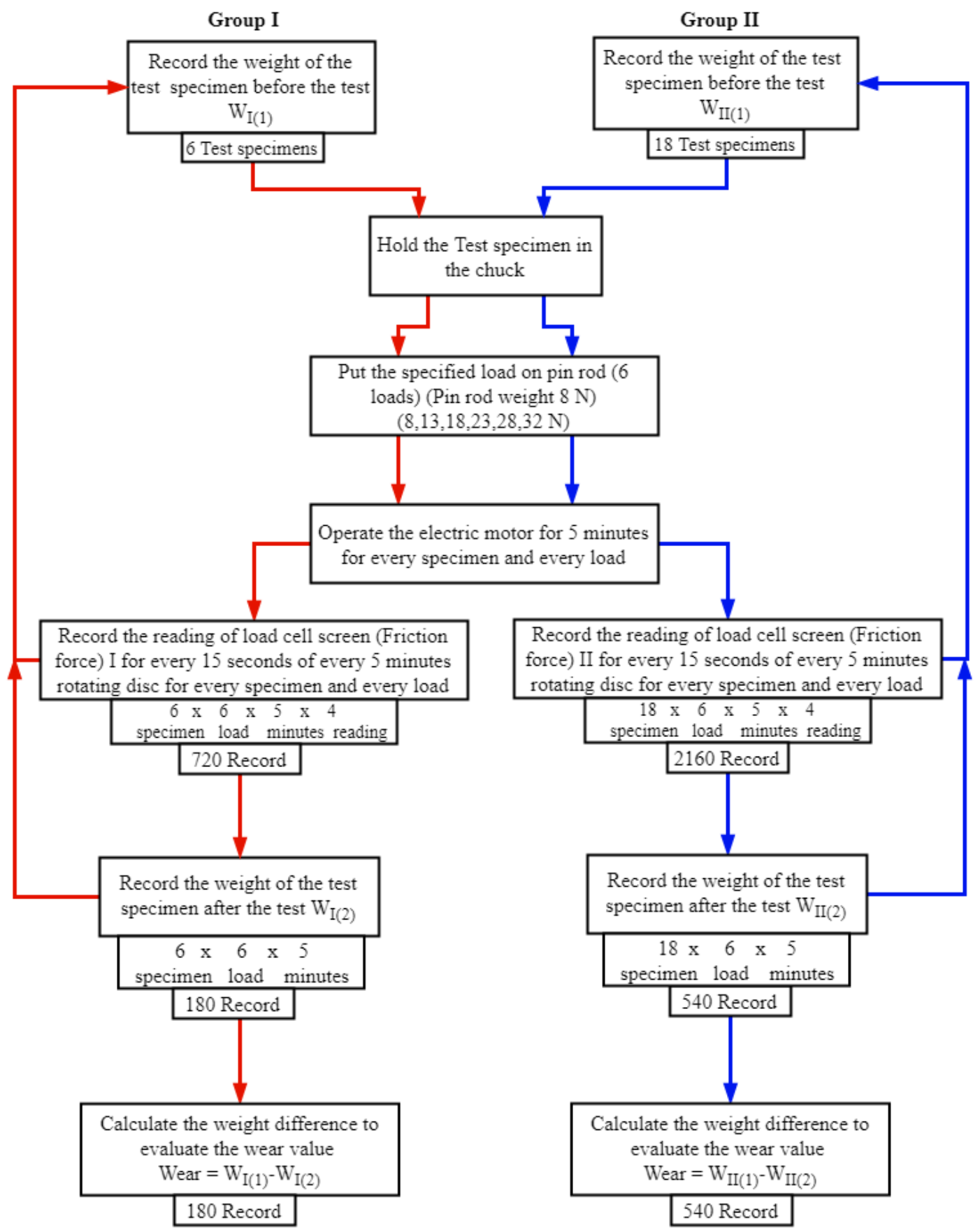

Figure 3 Flow chart of steps of measuring friction forces and wear loss 
After mixing the compound of group I in a special mould shown in Figure 4. The compound (inserted) in electrical furnace to $350^{\circ} \mathrm{c} /$ reacts for 10 Minutes. Melting the compound process in the mould should not repeated more than 2 times to avoid the burning of melt compound.

The casting composites were allowed to cool in air, then cut into cylindrical shape of constant diameter $8 \mathrm{~mm}$ and length $20 \mathrm{~mm}$ as shown in Figure 4to prepare the test specimens.

PE matric was used by using PET filling it by putting CNT of $0.2,0.4,0.6$, 0.8 and $1 \%$ content and added the paraffin oil of $0.3,0.5$ and $10 \mathrm{wt} \%$ for every percentage of CNT, as shown in Table 1. Then using a mixer to make the compound, the test specimen were molded in the mold shown in Figure 4.

\section{The previous steps are presented photography in Figure 4}

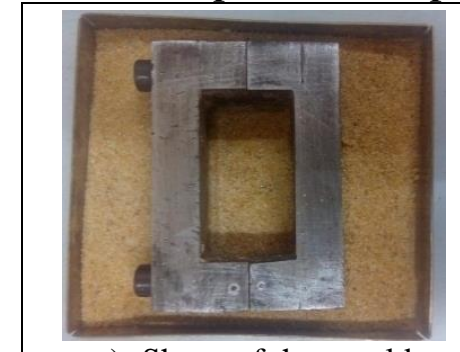

a) Shape of the mould assembled

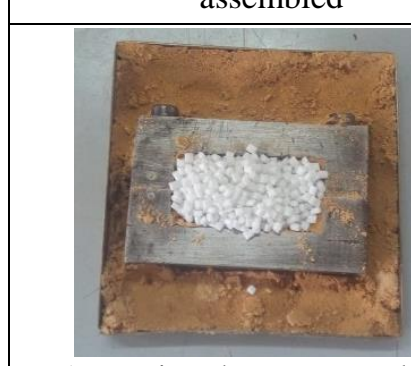

e) Putting the compound in the mould

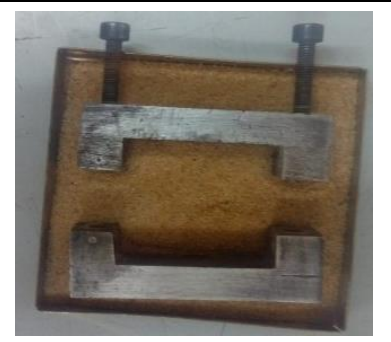

b) The mould disassembled into two halves

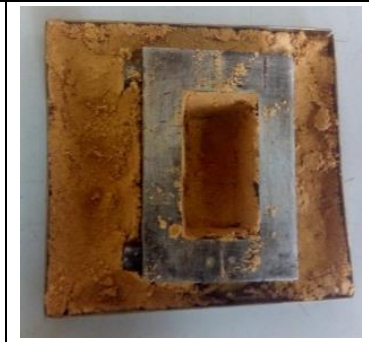

c) The mould with layer of sand

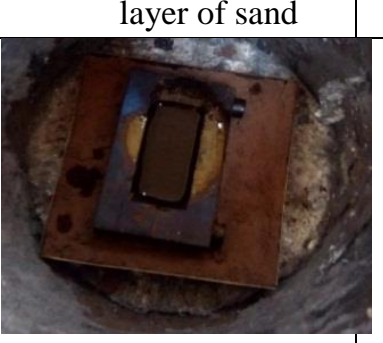

g) Mixing the compound in the mould

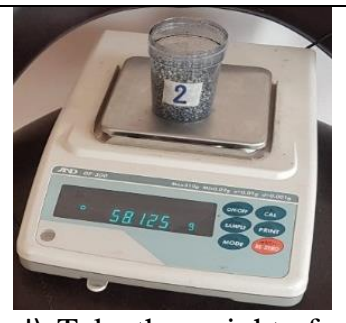

d) Take the weight of compound PET + CNT or $\mathrm{PET}+\mathrm{CNT}+$ Paraffin oil

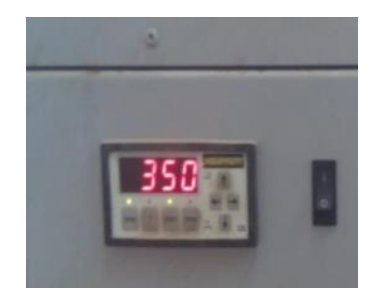

f) Inserting the mould in the electric furnace

h) Temperature of melting $350^{\circ} \mathrm{C}$

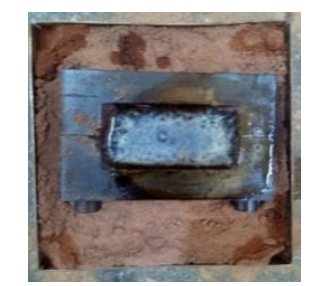

i) Extract the mould with the compound from the furnace

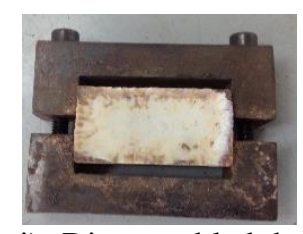

j) Disassembled the mould

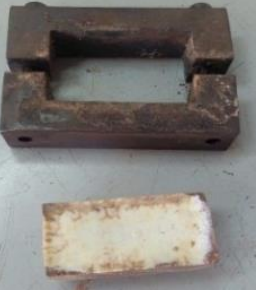

k) Take off the compound from mould

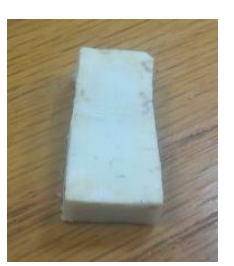

1) Cutting the compound to obtain the test specimen

Figure 4 Photographs for steps of preparing the test specimens.

m) The shape of the test specimen $20 \mathrm{~mm}$ length and $8 \varnothing \mathrm{mm}$

Group II: The second group of test specimens are composed from PET, CNT content and percentage of paraffin oil.

Using casting technique to prepare the compound of specimens with the percentage of each material as shown in the following Table 1. 
After cooling the compound of each test composite, cutting process by turning to obtain the cylindrical specimens with dimension $8 \mathrm{~mm}$ diameter and $20 \mathrm{~mm}$ length.

Table 1 Compound of PET with CNT and Paraffin oil (Group II)

\begin{tabular}{|c|c|c|c|c|c|c|c|c|c|}
\hline $\begin{array}{c}\text { Specimen } \\
\text { from } \\
\text { Group I }\end{array}$ & $\begin{array}{c}\text { CNT } \\
\text { Content } \\
\%\end{array}$ & $\begin{array}{c}\text { Specimen } \\
\text { Symbol }\end{array}$ & $\begin{array}{c}\text { Empty } \\
\text { Bottle } \\
\text { Weight }\end{array}$ & $\begin{array}{l}\text { Oil } \\
\%\end{array}$ & $\begin{array}{c}\text { Oil } \\
\text { Weight }\end{array}$ & $\begin{array}{c}\text { CNT } \\
\text { Weight }\end{array}$ & $\begin{array}{c}\text { PET } \\
\text { Weight }\end{array}$ & $\begin{array}{c}\text { Total } \\
\text { Weight }\end{array}$ & $\begin{array}{c}\text { Specimen } \\
\text { Weight }\end{array}$ \\
\hline \multirow{3}{*}{1} & \multirow{3}{*}{$\begin{array}{l}\text { Pure } \\
\text { PET }\end{array}$} & K1 & 2.84 & $3 \%$ & 1.5 & 0 & 48.5 & 52.84 & 50 \\
\hline & & L1 & 2.29 & $5 \%$ & 2.5 & 0 & 47.5 & 52.29 & 50 \\
\hline & & M1 & 2.83 & $10 \%$ & 5 & 0 & 45 & 52.83 & 50 \\
\hline \multirow{3}{*}{2} & \multirow{3}{*}{$0.20 \%$} & K3 & 2.74 & $3 \%$ & 1.5 & 0.1 & 48.4 & 52.74 & 50 \\
\hline & & L3 & 2.7 & $5 \%$ & 2.5 & 0.1 & 47.4 & 52.7 & 50 \\
\hline & & M3 & 2.78 & $10 \%$ & 5 & 0.1 & 44.9 & 52.78 & 50 \\
\hline \multirow{3}{*}{3} & \multirow{3}{*}{$0.40 \%$} & K4 & 2.79 & $3 \%$ & 1.5 & 0.2 & 48.3 & 52.79 & 50 \\
\hline & & L4 & 2.73 & $5 \%$ & 2.5 & 0.2 & 47.3 & 52.73 & 50 \\
\hline & & M4 & 2.42 & $10 \%$ & 5 & 0.2 & 44.8 & 52.42 & 50 \\
\hline \multirow{3}{*}{4} & \multirow{3}{*}{$0.60 \%$} & K5 & 2.4 & $3 \%$ & 1.5 & 0.3 & 48.2 & 52.4 & 50 \\
\hline & & L5 & 2.43 & $5 \%$ & 2.5 & 0.3 & 47.2 & 52.43 & 50 \\
\hline & & M5 & 2.43 & $10 \%$ & 5 & 0.3 & 44.7 & 52.43 & 50 \\
\hline \multirow{3}{*}{5} & \multirow{3}{*}{$0.80 \%$} & K6 & 2.43 & $3 \%$ & 1.5 & 0.4 & 48.1 & 52.43 & 50 \\
\hline & & L6 & 2.42 & $5 \%$ & 2.5 & 0.4 & 47.1 & 52.42 & 50 \\
\hline & & M6 & 2.42 & $10 \%$ & 5 & 0.4 & 44.6 & 52.42 & 50 \\
\hline \multirow{3}{*}{6} & \multirow{3}{*}{$1 \%$} & K7 & 2.38 & $3 \%$ & 1.5 & 0.5 & 48 & 52.38 & 50 \\
\hline & & L7 & 2.4 & $5 \%$ & 2.5 & 0.5 & 47 & 52.4 & 50 \\
\hline & & M7 & 2.4 & $10 \%$ & 5 & 0.5 & 44.5 & 52.4 & 50 \\
\hline
\end{tabular}

\section{Results and Discussion}

With the constructed pin on disk test rig, the friction coefficient and wear loss values are recorded and determined under variable applied loads for the two groups of compounds of PET and CNT for group I and PET, CNT and paraffin oil for group II .

Tests are carried out using rotating disk of $19 \mathrm{~mm}$ diameter and a pin as a test specimen of $8 \mathrm{~mm}$ diameter and $20 \mathrm{~mm}$ length made from each compound with specified percentage content from previous materials under applied load $(8,13,23$, $28,33 \mathrm{~N})$.

Using the facilities offered by the design test rig and measuring techniques, two groups of tests could be carried out on the two groups of the test specimens namely friction coefficient which taken from the load cell screen every 15 seconds for 5 minutes of rotating disk under applied loads ranging from $8 \mathrm{~N}$ to $33 \mathrm{~N}$, then obtain the friction coefficient. The other group of tests are calculate the wear loss values by recording the weight of every test specimen for the two groups before and after 5 minutes of disk rotation under the same applied load and table the difference between the two weights to calculate the wear loss value occurred.

From Experimental records which carried out, it could be seen that introducing percentage of (CNT) to (PET) or adding percentage of paraffin oil with a content of (PET) and (CNT) presented a described characteristics. 


\subsection{Friction Coefficient Analysis:-}

The friction coefficient values for percentage CNT added to PET and percentage of paraffin oil are shown in figures (5-10). It can he observed that tests with specimens without paraffin oil (Zero \%) gives higher values of the friction coefficient. Introducing percentages of paraffin oil with values $(3 \%, 5 \%, 10 \%$ wt.), shows lowering of friction coefficient at increasing the applied loads. Lower values of friction coefficient approximately was detected at $23 \mathrm{~N}$ applied load and $10 \% \mathrm{wt}$ paraffin oil and $0.2 \%$ CNT, Increasing the applied load after $28 \mathrm{~N}$, there is slight increase of friction coefficient, figure.

Comparison of results with results of AZ31 alloy reinforced by CNT [29] showed similar trend of lowering FC with increasing applied load at similar applied loads. This can be attributed to the increase in ploughing force and penetration in the samples at higher applied load condition, which can generate more pull out of CNTs from the matrix, leading to the improvement of lubrication efficiency of carbon film. Another comparison of tests with tests carried out for behavior of epoxy reinforced with CNC and filled by paraffin oils [30, 31], showing similar trends, as increasing percentage of CNT lowering friction coefficient, figures (5-10) the relationship between FC and CNT for the same content of CNT, figures (11-16) shows decreasing of FC with increasing applied loads or increasing CNTs content at the same load. This might be attributed to self-lubricating mechanism during tests.

Presence of oil in multi pores inside the compound work as reservoirs of oil and leak up the sliding surface and can be responsible of decreasing friction coefficient. The model for adopting and fits the curves of friction coefficient versus CNT contents and fit friction coefficient versus loads at different percentage of paraffin oil, Figures (5-10) and figures (11-16).

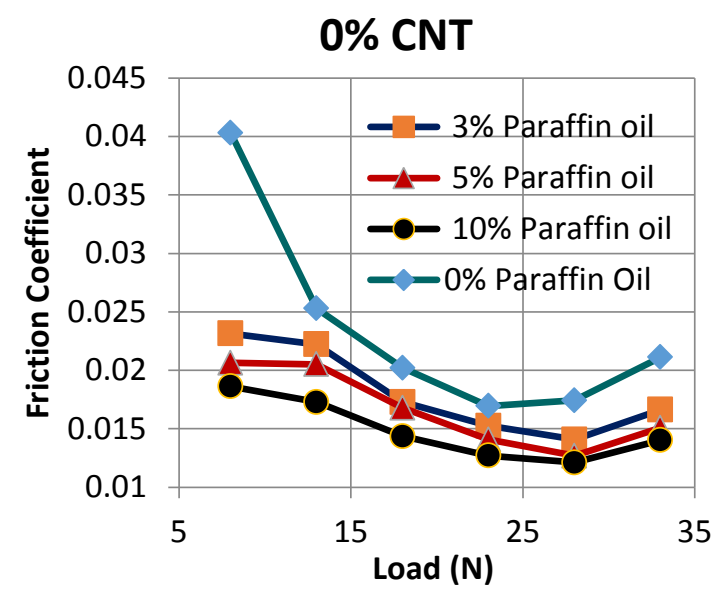

Figure 5 Variation of Friction Coefficient as a function of applied load for different percentages of Paraffin Oil at $0 \%$ CNT

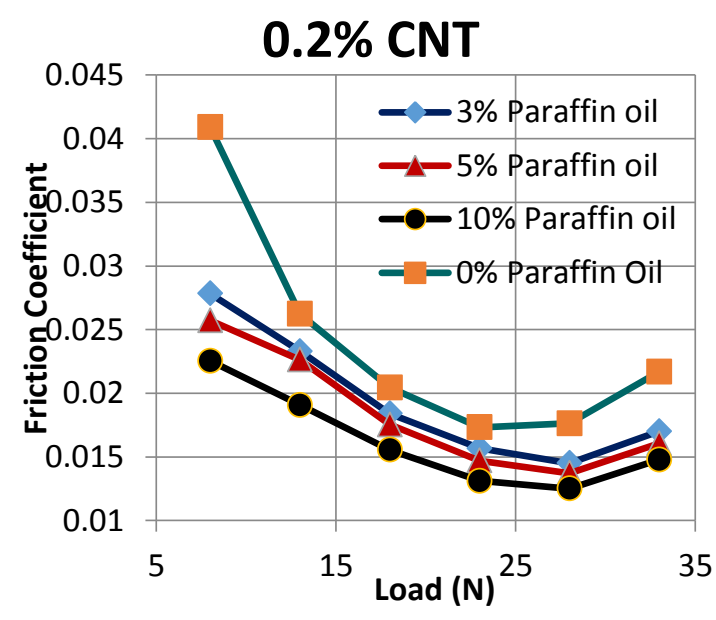

Figure 6 Variation of Friction Coefficient as a function of applied load for different percentages of Paraffin Oil at $0.2 \%$ CNT 


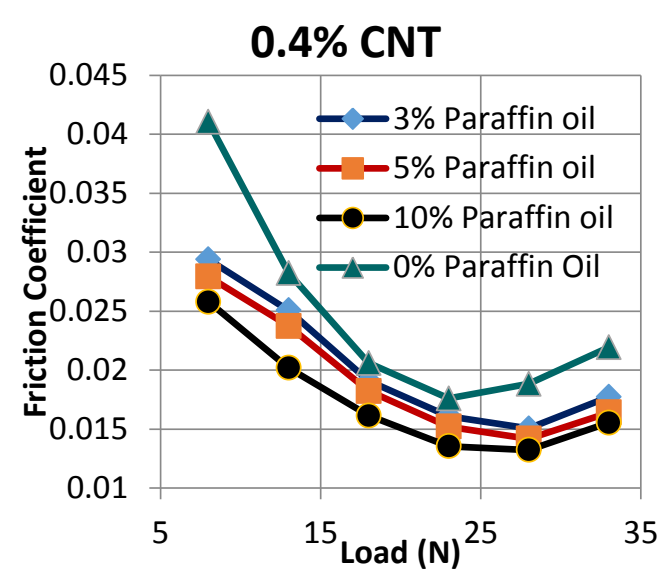

Figure 7 Variation of Friction Coefficient as a function of applied load for different percentages of Paraffin Oil at $0.4 \%$ CNT

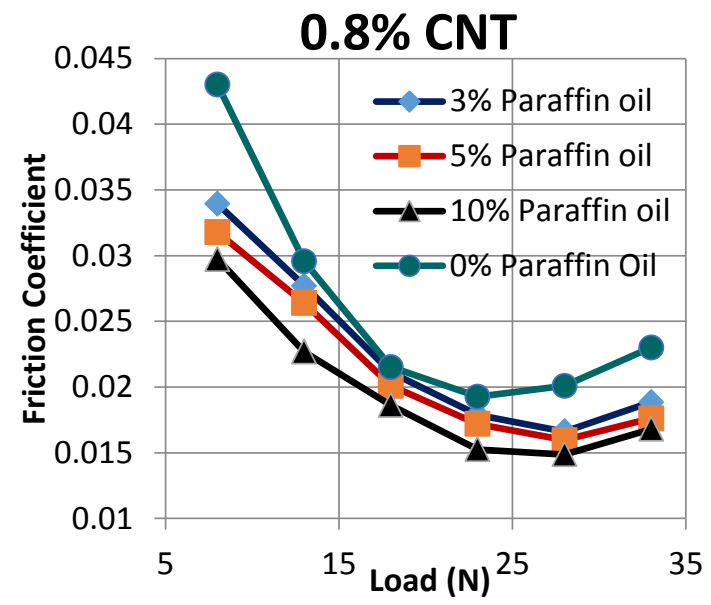

Figure 9 Variation of Friction Coefficient as a function of applied load for different percentages of Paraffin Oil at $0.8 \%$ CNT

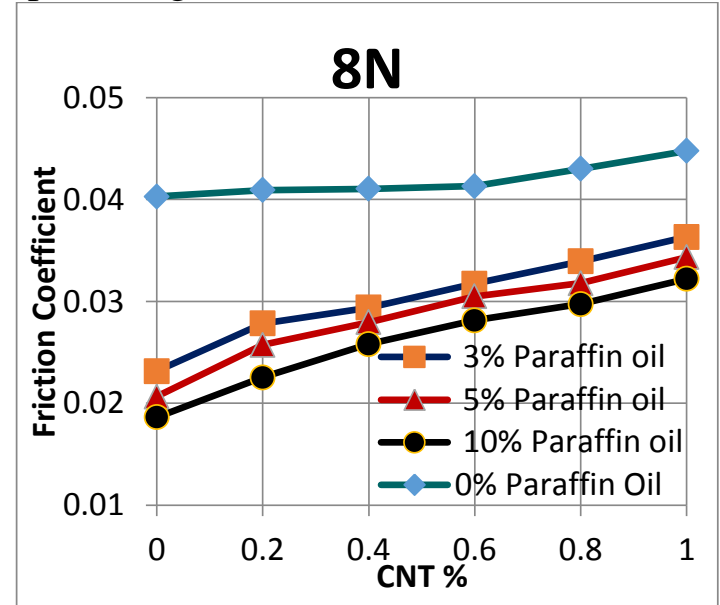

Figure 11 Variation of Friction Coefficient as a function of CNT \% for percentages of Paraffin oil at $8 \mathrm{~N}$ load

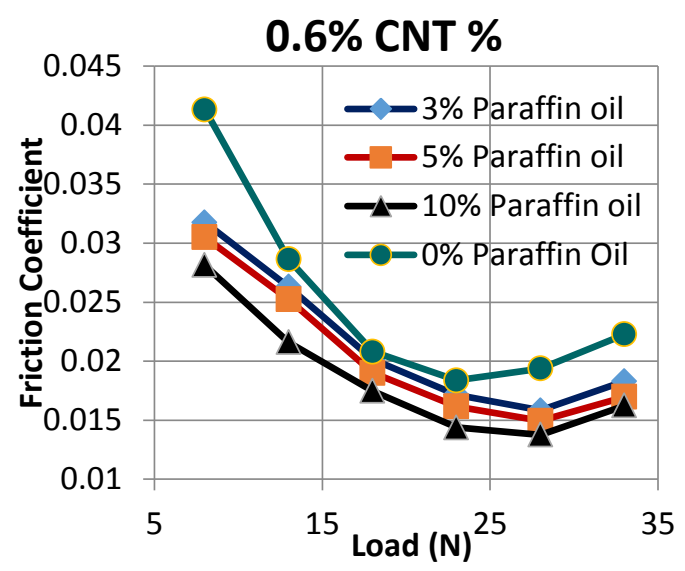

Figure 8 Variation of Friction Coefficient as a function of applied load for different percentages of Paraffin Oil at $0.6 \%$ CNT

\section{$1 \%$ CNT}

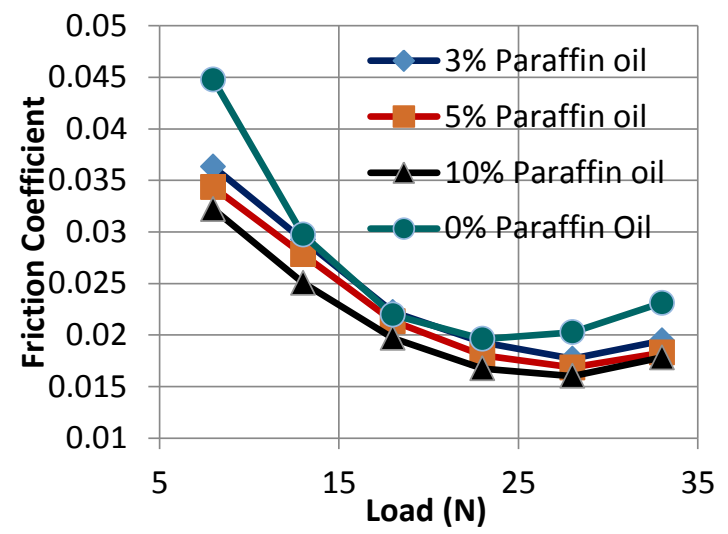

Figure 10 Variation of Friction Coefficient as a function of applied load for different percentages of Paraffin Oil at 1\% CNT

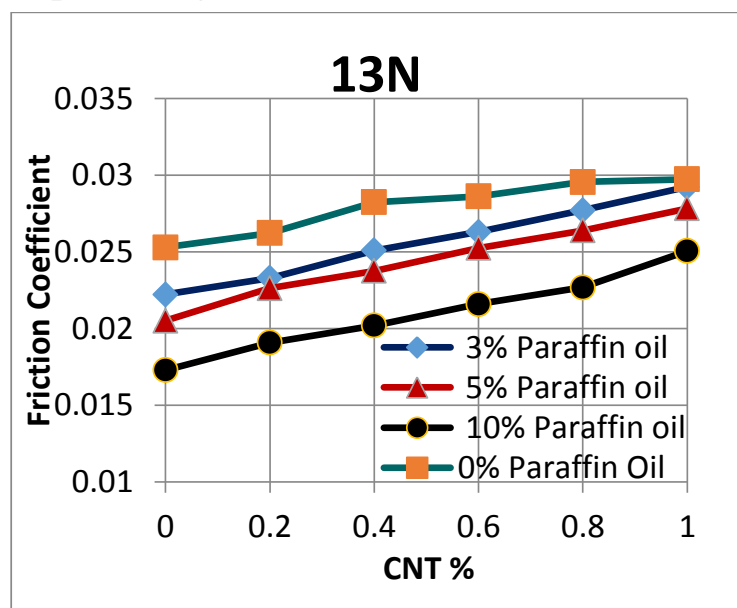

Figure 12 Variation of Friction Coefficient as a function of CNT \% for percentages of Paraffin oil at $13 \mathrm{~N}$ load 


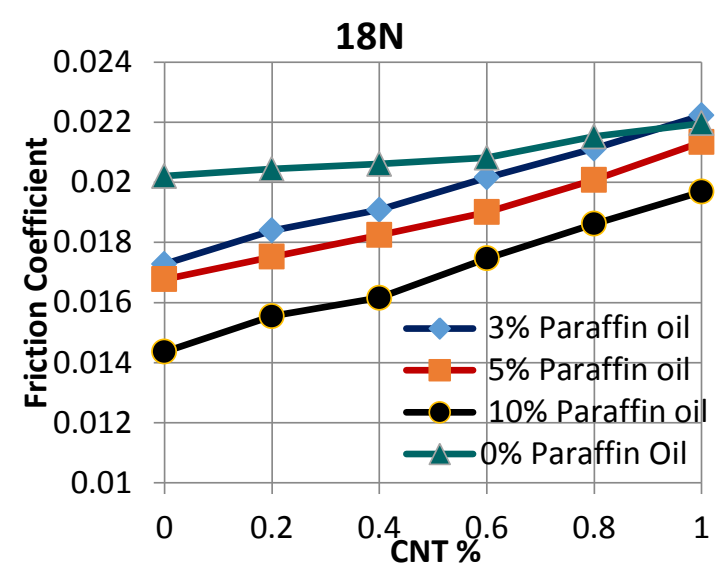

Figure 13 Variation of Friction Coefficient as a function of CNT \% for percentages of Paraffin oil at $18 \mathrm{~N}$ load

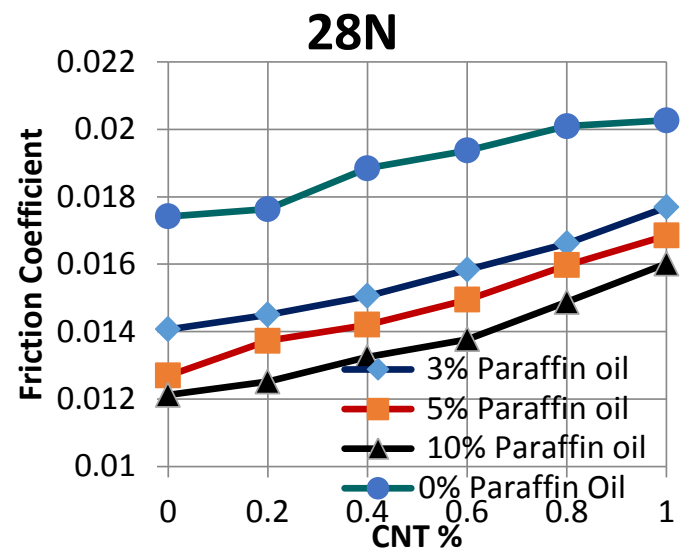

Figure 15 Variation of Friction Coefficient as a function of CNT \% for percentages of

Paraffin oil at $28 \mathrm{~N}$ load

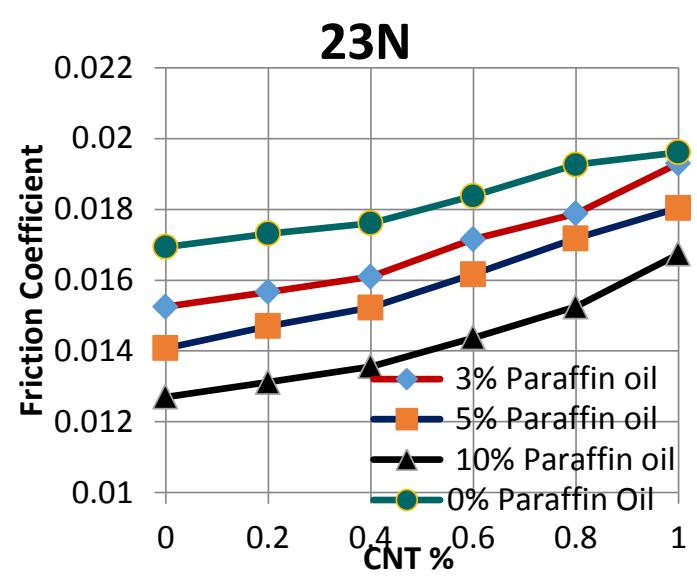

Figure 14 Variation of Friction Coefficient as a function of CNT \% for percentages of Paraffin oil at $23 \mathrm{~N}$ load

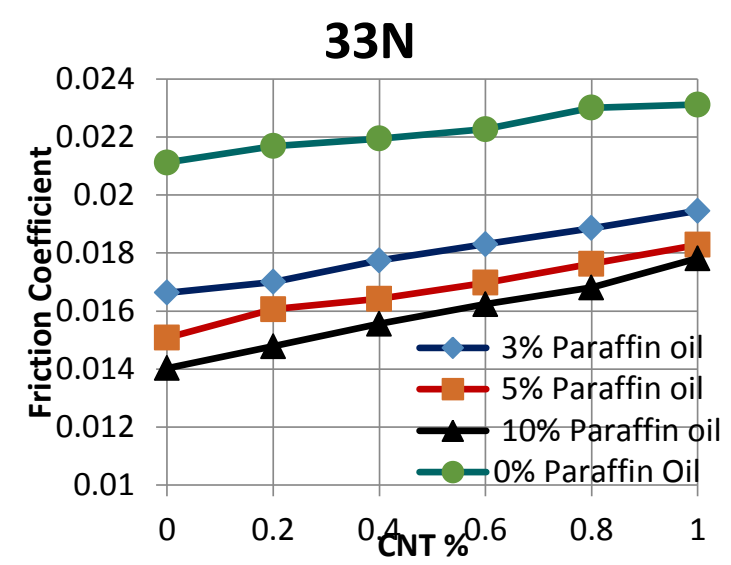

Figure 16 Variation of Friction Coefficient as a function of CNT \% for percentages of

Paraffin oil at $33 \mathrm{~N}$ load

\subsection{Wear as a Weight Loss Behaviors.}

Figures (17-22) illustrate the effect the load and percentage of zero percentage paraffin oil and 3\%,5\%,10\% paraffin oil at CNT content on the weight loss or wear mass loss. It can be detected that wear mass loss of the composite decreases with that the significantly with the increase of applied loads Figures (23-28) showed the effect of the amount of CNT and the previous percentage of paraffin oil at several loads on wear mass loss.

It can be observed that the wear mass loss of the compound decreases with increases of CNT percentage. With the increase of percentage of paraffin oil, it is evident from present curves, figures (23-28) that the wear mass loss decreases. This can be attributed to the following aspects (a) the addition of CNT can improve the hardness and strength of the compound, which lowering the weight loss, (b) the self-lubrication effect of CNT which decreases friction coefficient of the composites in the compound, then decrease the weight loss $[32,33]$, (c) the influence of applied loads, the ploughing effect increases with the increases of load value, leading to increase of the weight loss; (d) more pulled-out CNT can be brought into friction 
surface due to a higher ploughing force at higher loads resulting in better effect of weight loss.

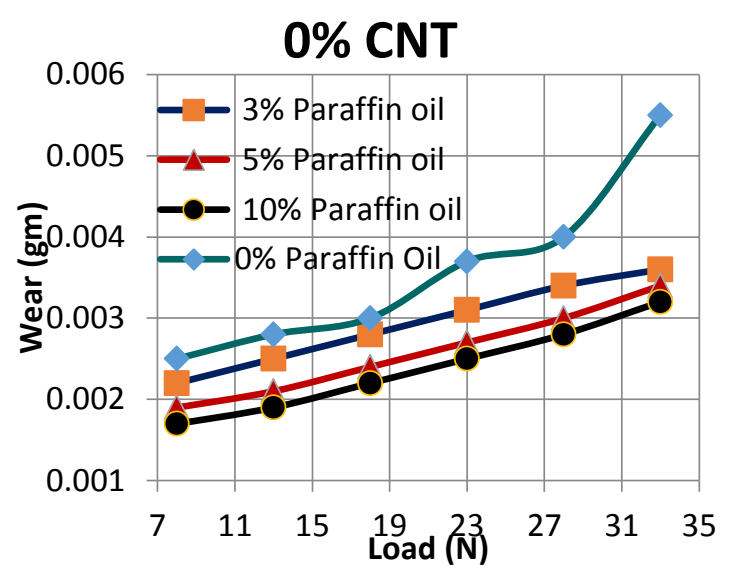

Figure 17 Variation of Wear as a function of applied load for different percentages of

Paraffin Oil at $0 \%$ CNT

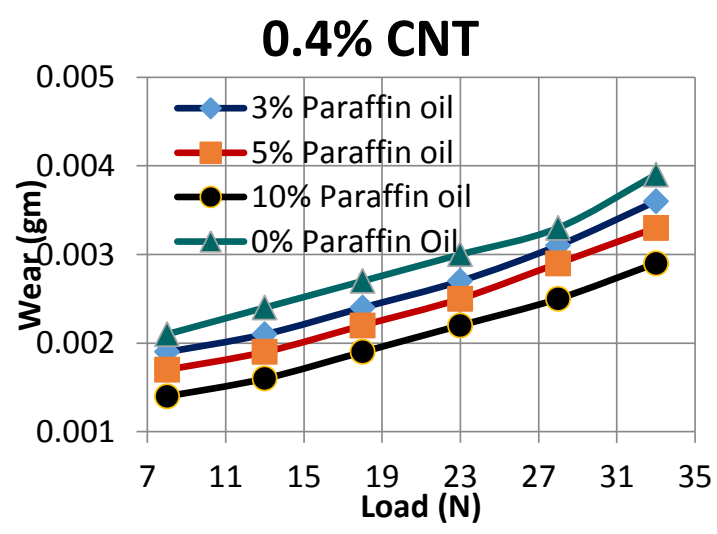

Figure 19 Variation of Wear as a function of applied load for different percentages of Paraffin Oil at $0.4 \%$ CNT

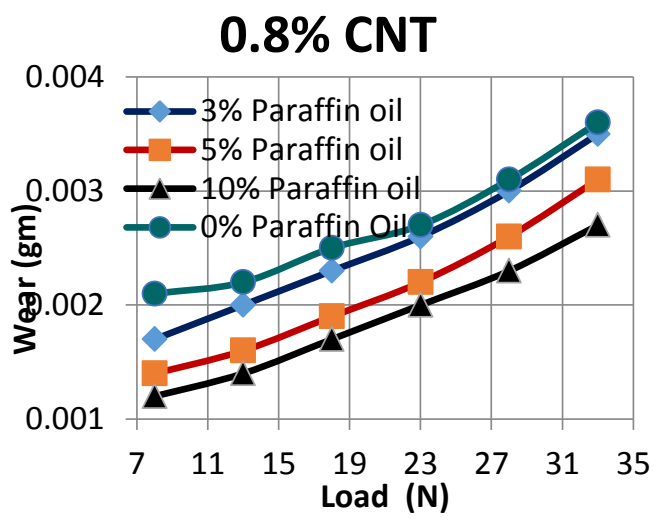

Figure 21 Variation of Wear as a function of applied load for different percentages of Paraffin Oil at $0.8 \%$ CNT

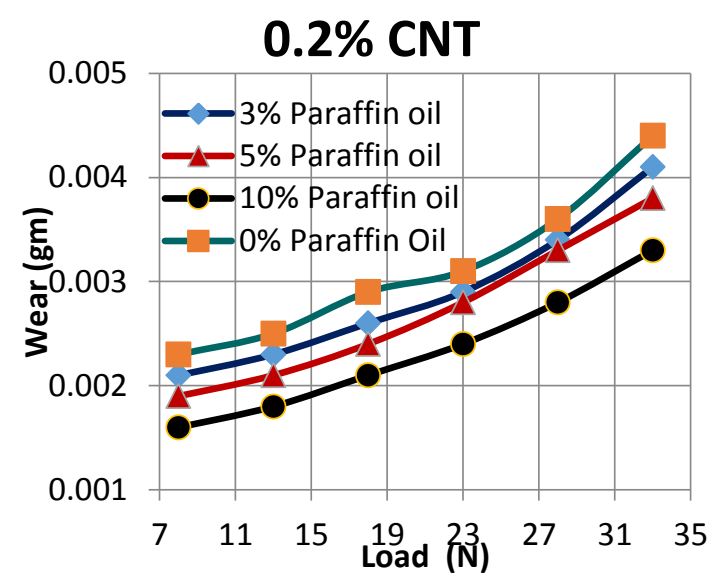

Figure 18 Variation of Wear as a function of applied load for different percentages of Paraffin Oil at $0.2 \%$ CNT

\section{$0.6 \%$ CNT}

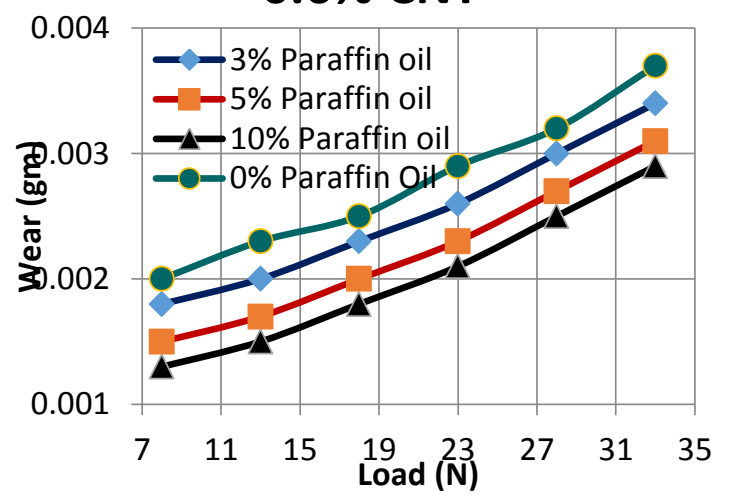

Figure 20 Variation of Wear as a function of applied load for different percentages of

Paraffin Oil at $0.6 \%$ CNT

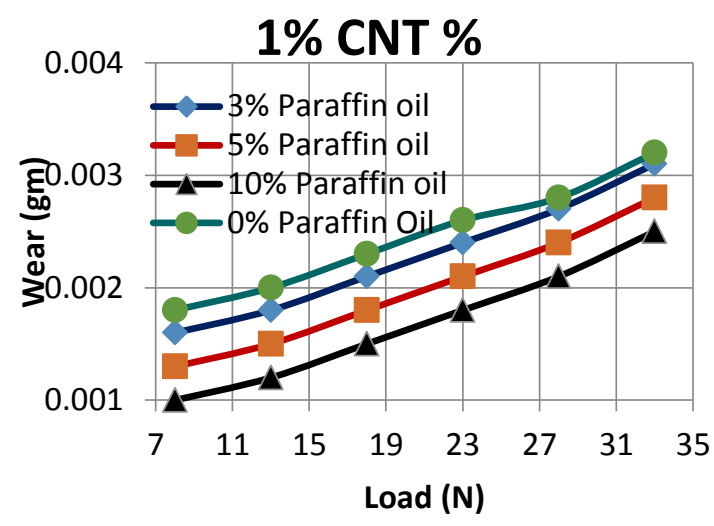

Figure 22 Variation of Wear as a function of applied load for different percentages of

Paraffin Oil at $1 \%$ CNT 


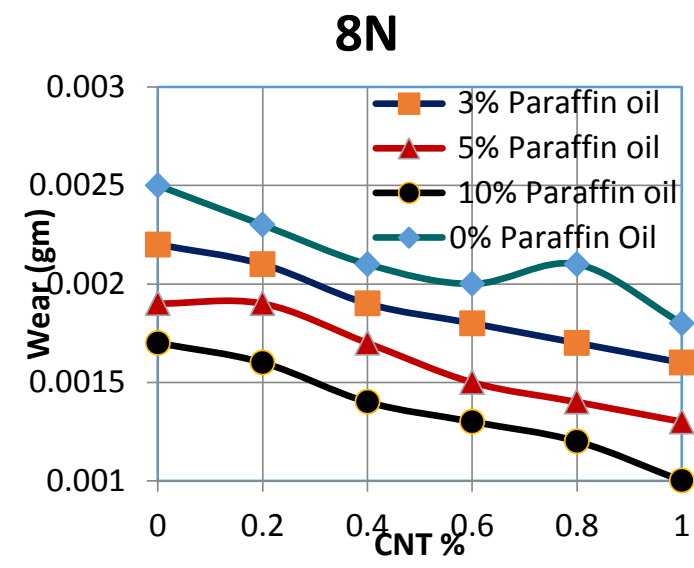

Figure 23 Variation of Wear as a function of CNT \% for percentages of Paraffin oil at $8 \mathrm{~N}$ load

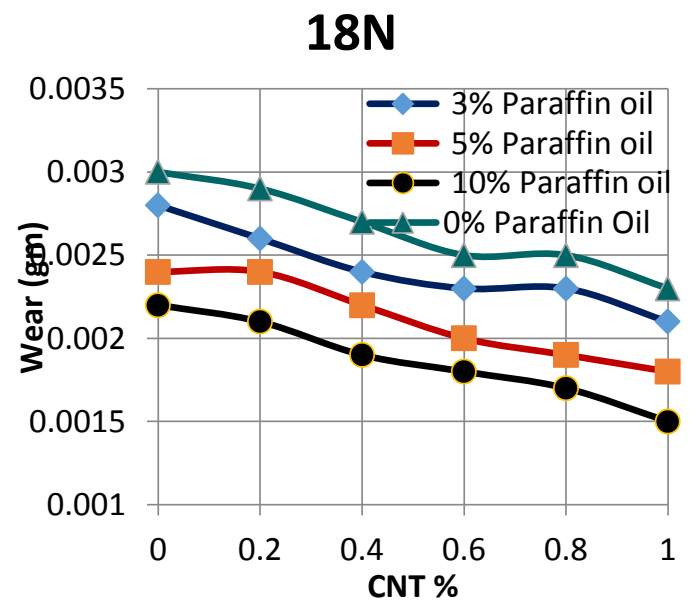

Figure 25 Variation of Wear as a function of CNT \% for percentages of Paraffin oil at $18 \mathrm{~N}$ load

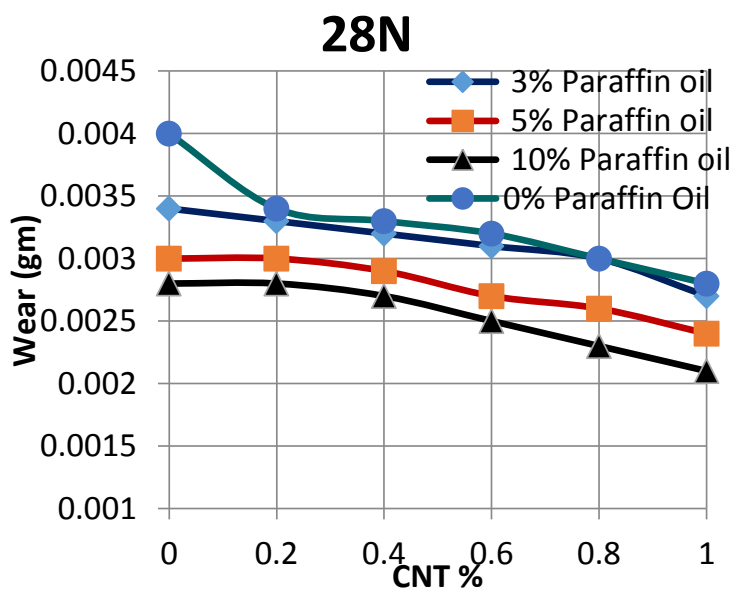

Figure 27 Variation of Wear as a function of CNT \% for percentages of Paraffin oil at $28 \mathrm{~N}$ load

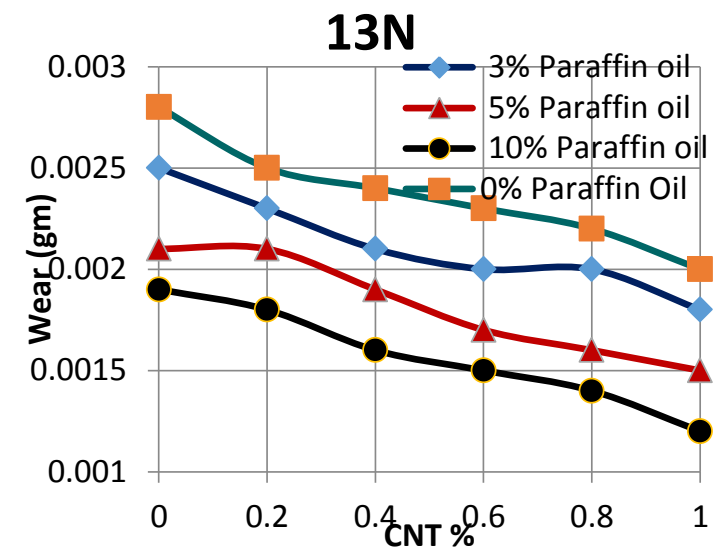

Figure 24 Variation of Wear as a function of CNT \% for percentages of Paraffin oil at $13 \mathrm{~N}$ load

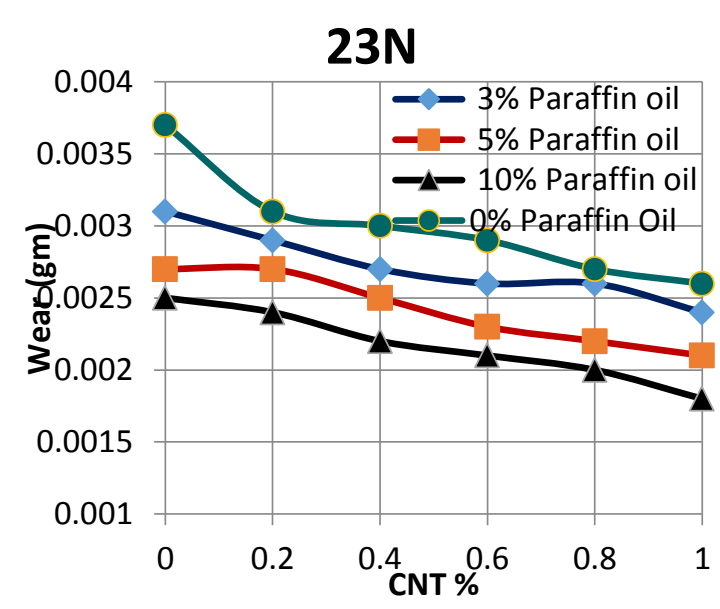

Figure 26 Variation of Wear as a function of CNT \% for percentages of Paraffin oil at $23 \mathrm{~N}$ load

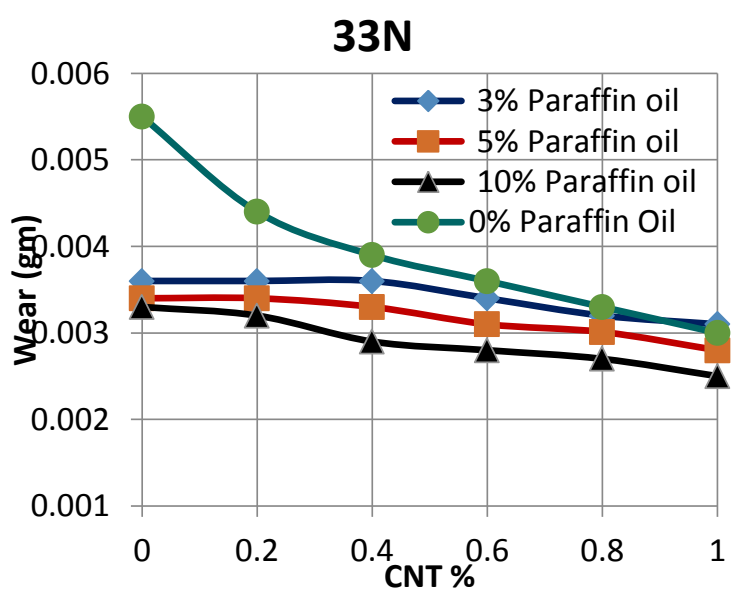

Figure 28 Variation of Wear as a function of $\mathrm{CNT} \%$ for percentages of Paraffin oil at $33 \mathrm{~N}$ load 
CNT have been widely used as a filler material for composites due to superior mechanical properties.

Mechanical properties were evaluated by using universal tension test machine at the room temperature. Tensile tests were carried out with eight composites as shown in Table 2. The hardness numbers are measured using Rockwell test device (1.6 mm ball diameter).

The mechanical properties of PET Nano composites with CNT and adding wt $\%$ of Paraffin oil are shown in Figure $29,30 \& 31$. The tensile strength, elongation breaks $\%$ and hardness increased significantly with increasing the CNT content from $0.2 \mathrm{wt} \%$ to $1 \mathrm{wt} \%$ and Paraffin oil from $3 \mathrm{wt} \%$ to $10 \mathrm{wt} \%$ due to the Nano reinforcing effect of CNT with high aspect ratio [34].

Table 2 Mechanical properties of tested Material Mixture

\begin{tabular}{|c|c|c|c|c|c|c|c|}
\hline $\begin{array}{l}\text { Material } \\
\text { Composites }\end{array}$ & $\begin{array}{l}\text { Pure } \\
\text { CNT }\end{array}$ & $\begin{array}{c}\text { PET } \\
+0.2 \mathrm{wt} \% \\
\text { CNT }\end{array}$ & $\begin{aligned} & \text { PET } \\
&+ 1 \mathrm{wt} \% \\
& \text { CNT }\end{aligned}$ & $\begin{array}{c}\text { PET }+ \\
0.2 \mathrm{wt} \% \\
\text { CNT }+ \\
3 \% \text { Paraffin } \\
\text { Oil }\end{array}$ & $\begin{array}{c}\text { PET + } \\
0.2 \mathrm{wt} \% \\
\mathrm{CNT}+ \\
10 \% \\
\text { Paraffin Oil }\end{array}$ & $\begin{array}{c}\text { PET }+ \\
1 \mathrm{wt} \% \text { CNT } \\
+ \\
3 \% \text { Paraffin } \\
\text { Oil }\end{array}$ & $\begin{array}{c}\text { PET }+ \\
1 \mathrm{wt} \% \text { CNT } \\
+ \\
10 \% \\
\text { Paraffin Oil }\end{array}$ \\
\hline $\begin{array}{c}\text { Tensile } \\
\text { Strength } \\
\mathrm{MPa}\end{array}$ & 60 & 73 & 79 & 71 & 69 & 76 & 72 \\
\hline $\begin{array}{l}\text { Elongation } \\
\text { at Break \% }\end{array}$ & 80 & 20.5 & 16.2 & 18 & 22 & 24 & 26 \\
\hline $\begin{array}{l}\text { Hardness } \\
\text { (HRB) }\end{array}$ & 106 & 122 & 135 & 118 & 110 & 131 & 129 \\
\hline
\end{tabular}

\section{Conclusion}

Of polymeric composites CNT, percentage reinforced PET content and with adding percentage paraffin oil, the friction coefficient and wear loss has been investigated. As regards on the behavior and analysis of test results, conclusion can be detected as follows:

1- Molding method could successfully fabricated a matrix of CNT reinforced PET with uniform distribution of proper content.

2- Adding CNT and paraffin oil could significantly decreases friction coefficient and mass loss of the matrix of PET/CNTs and provide the composites by self lubricating effect on the sliding surface, where carbon and oil film cover the contact area.

3- Wear resistance of PET and CNT composites was improved by adding contents of CNT and paraffin oil due to the reinforcing effect and good thermal conductively of CNTs. Wear rate of the composites decreases with increasing CNTs content to $1.0 \mathrm{wt}$. \% and increasing the percentage of paraffin oil to $10 \mathrm{wt}$. $\%$.

4- By adding Paraffin oil with 3, 5, $10 \mathrm{wt} \%$ could significantly decrease the friction coefficient from 0.02 to 0.017 with average percentage $53 \%$ at zero content of CNT. By increasing the CNT 0.2, 0.4, 0.6, 0.8 and $1 \mathrm{wt} \%$ and increasing Paraffin 
oil 3,5 and $10 \mathrm{wt} \%$, the friction coefficient reached a lower value of 0.015 at a load $33 \mathrm{~N}$ and $0.6 \% \mathrm{CNT}$.

5- The tensile strength of PET reinforced by $0.2 \mathrm{wt} \% \mathrm{CNT}$ and 1 wt \% CNT increases from 22 to $32 \%$. By increasing wt $\%$ of Paraffin oil to the composite of $0.2 \mathrm{wt} \%$ to $1 \mathrm{wt} \% \mathrm{CNT}$ from $3 \mathrm{wt} \%$ to $10 \mathrm{wt} \%$ showed improvement of tensile strength from 15 to $26 \%$ and elongation at break $\%$ by $30 \%$ while the hardness increases from 6 to $24 \%$ (HRB).

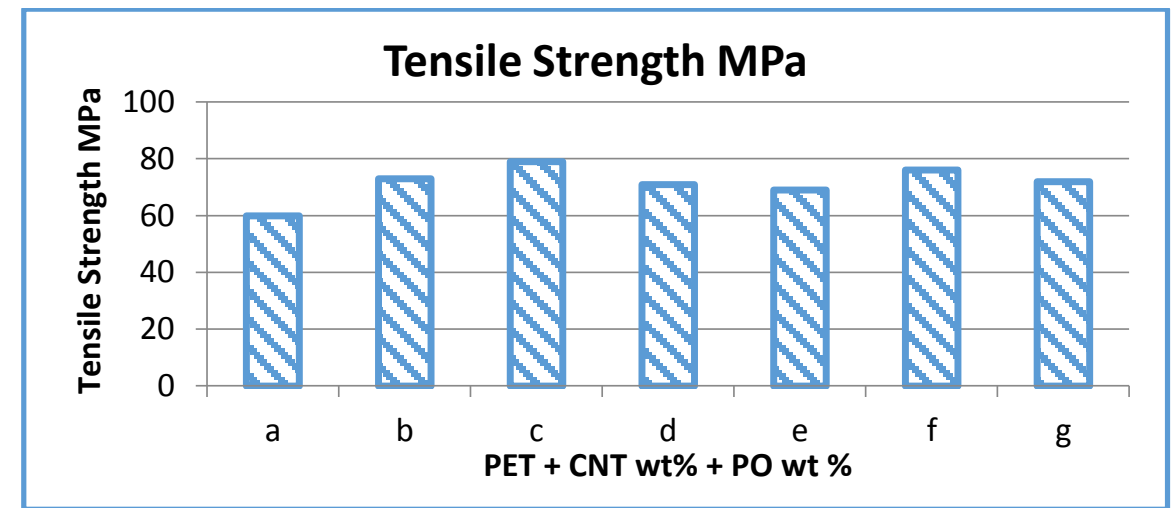

Figure 29 Tensile Strength of PET, PET containing CNT and PET containing CNT \& Paraffin oil

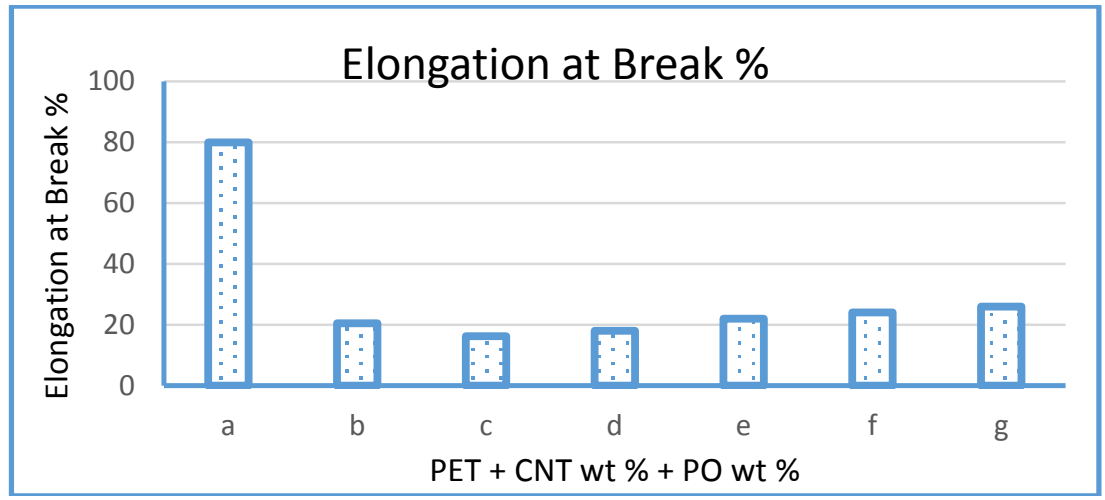

Figure 30 Elongation at break \% of PET, PET containing CNT and PET containing CNT \& Paraffin oil

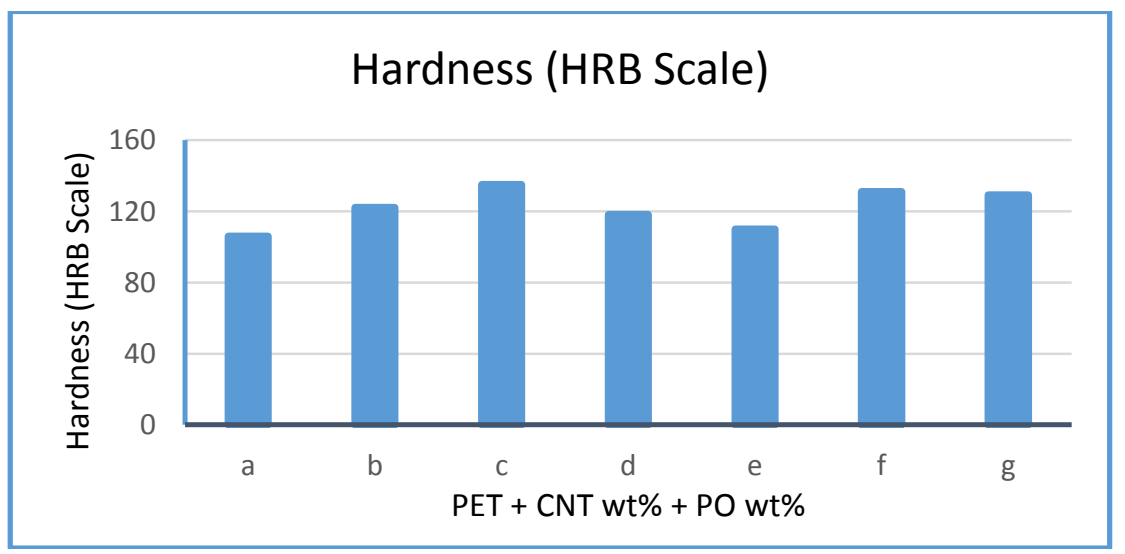

Figure 31 Hardness of PET, PET containing CNT and PET containing CNT \& Paraffin oil 


\begin{tabular}{|c|c|c|c|c|c|c|}
\hline $\mathrm{a}$ & $\mathrm{b}$ & $\mathrm{c}$ & $\mathrm{d}$ & $\mathrm{e}$ & $\mathrm{f}$ & $\mathrm{g}$ \\
\hline & & & PET + & PET + & PET + & PET + \\
Pure & PET & PET & $0.2 \mathrm{wt} \%$ & $0.2 \mathrm{wt} \%$ & $1 \mathrm{wt} \% \mathrm{CNT}$ & $1 \mathrm{wt} \% \mathrm{CNT}$ \\
CNT & $+0.2 \mathrm{wt} \%$ & $+1 \mathrm{wt} \%$ & CNT + & $\mathrm{CNT}+$ & + & + \\
& CNT & CNT & $3 \%$ Paraffin & $10 \%$ & $3 \%$ Paraffin & $10 \%$ \\
& & & Oil & Paraffin Oil & Oil & Paraffin Oil \\
\hline
\end{tabular}

\section{References}

1. G. Staab, "Laminar composites, " ed : Butterworth-Heinemann, Boston, 1999.

2. J. Jordan, K. I. Jacob R. Tannenbaum, M.A. Sharaf, and I. Jasiuk: "Experimental trends in polymer nanocomposites-a review, "Materials science and Engineering : A, vol. 393, pp. $1-11,2005$.

3. X. sun, H. sun, H.li, and H. Peng: "Developing polymer composite materials: carbon nanotubes or graphene?" Advanced Materials, vol. 25, pp. 5153-5176, 2013.

4. B. K. Kaushik and M. K. Majumders "Carbon Nanotube: Properties and Applications", Springe, Brief in Applied sciences and Technology, vol. 10.1007/978-81-322-2047-3-2, 2015.

5. N. G. sahoo, S. Rana, J. W. Cho, L, Li, and S. H. Chan: "Polymer nanocomposites based on functionalized carbon nanotubes," Progress in polymer science. Vol. 35, pp. 837-867, 2010.

6. J.M. Margolis: Conductive Polymers and plastics. London: Chapman \& Hall, 1989.

7. D. Chung: "Electrical applications of carbon materials, "Journal of Materials science, vol. 39, pp. 2645-2661, 2004.

8. R. Sengupta, M. Bhattacharya, S. Bandyopadhyay, and A.K.Bhowmick : "A review on the mechanical and electrical properties of graphite and modified graphite reinforced polymer composites, “ Progress in Polymer Science. Vol. 36, pp. 638-670, 2011.

9. S. Paul and D.-w. Kim: "Preparation and characterization of highly conductive transparent films with single-walled carbon nanotubes for flexible display applications," Carbon, vol. 47, pp. 2436-2441, 2009.

10. F. Hussain, M. Hojjati, M. Okamoto, and R. E. Gorga: "Review article: polymer matrix nanocomposites, processing, manufacturing and application: an overview, "Journal of Composite Materials, vol. 40, pp. 1511-1575, 2006.

11. Iijima S.,: " Helical microtubules of graphitic carbon, " Nature vol. 354,pp.56-58, 1991.

12. P.J. Harris: Carbon Nanotube Science: Synthesis, Properties and Applications. USA: Cambridge University Press, 2009.

13. T. Erik, Z. Ren, and T. w. Chou: "Advances in the science and technology of carbon nanotubes and their composites: A review, "composites Science, 2001.

14. P. C. Ma, N.A. Siddiqui, G. Marom, and J.K. Kim: "Dispersion and functionalization of carbon nanotubes for polymer based nanocomposites: A review," Composites Part A: Applied Science and Manufacturing, vol. 41, pp. 1345-1367, 2010.

15. F. Hussain, M. Hojjati, M. Okamoto, and R.E. Gorga: "Review article: Polymermatrix nanocomposites, processing, manufacturing, and application: An overview, "Journal of Composite Materials, vol. 40, pp. 1511-1575, 2006.

16. Darina Ondrusova and Eugen Jona : "New Polymer Nano Fillers Based on Modified Forms of Zeolite", Chemistry 107, S101-S202, 2013.

17. Huu-Duc Nguyen- Tran, Van - Tho Hoang, Van - Ta Do: Doo - Man Chun and Young Jin Yum: "Effect of Multi walled Carbon Nanotubes on the Mechanical Properties of Carbon fiber reinforced Polymide - 6/ Poly propylene composites for light weight Automotive Parts, “ Materials 2018, 11, 429, vol-10.3390/ma 11030429.

18. M. Moniruzzaman, and, K. I. Winey: "Polymer Nanocomposites containing Carbon Nanotubes, "Macromolecules, vol. 39,pp. 5194-5205, 2006/08/01. 2006.

19. J. N. Coleman, U. Khan, W. J. Blau, and Y.K. Gun. ko: "Small but strong: A review of the mechanical properties of carbon nanotube-polymer composites, "carbon vol.44, pp.1624-1652, 2006. 
20. M. K. Yeh, T.-H. Hsieh, and N.-H. Tai: "Fabrication and mechanical properties of multiwalled carbon nanotubes/epoxy nanocomposites," Materials Science and Engineering: A, vol.483-484, pp.289-292, 2008.

21. T. Guo, P. Nikolaev, A. G. Rinzler, D. Tomanek D.T. Colbert, and R.E. Smalley: "SelfAssembly of tubular fullerenes," The Journal of Physical Chemistry, vol. 99, pp.109410697,1995/07/01, 1995.

22. J. Tavares, E. J. Swanson, and, and S. Coulombe: "Plasma synthesis of Coated Metal Nanoparticles with surface properties tailored for Dispersion, "Plasma Processes and Polymers, vol. 5, pp. 759-769, 2008.

23. R. Sengupta, M. Bhattacharya, S. Bandyopadhyay, and A. K. Bhowmick: "A review on the mechanical and electrical properties of graphite and modified graphite reinforced polymer composites, "Progress in polymer science, vol . 36, pp. 638-670, 2011.

24. Atsush : Hirata and Nobuaki Yoshioka : "Sliding Friction Properties of Carbon Nano Tube Coating Deposited by Microwave Plasma Chemical Vapor Deposition", Tribology International 37, pp. 893 - 898, 2004.

25. J.J.Hu., S.H.Jo, Z.F.Ren, A.A.Woevodin and J.S.Zabinski: "Tribological Behaviour and Graphitization of Carbon Nano Tube Grown on 440 C Stainless steel," Tribology Letters, Vol.19, No.2, June Feb. 2005.

26. Mazeyar Parvinzadeh, Siamak Moradian, Abosaeed Rashidi and Mohamed - Esmail Yazdans henas : "Surface Characterization of Polyethylene Terephthalate / silica Nano Composites", Applied Surface Science, 256, pp. 2792 - 2802, 2010.

27. K.S.Kanaga Karufpiah, Angela L., Bruck, Sriran Sundararajan, Jun Wang, Zhigun Lin, Zhi-Hui Xu and Xiaodong Li : "Friction and Wear Behaviour of Ultra High Molecular weight Polyethylene as a Function of Polymer Crystallinity", Science Direct, Acta Biomateriallia, 4, pp. 1401-1410, 2008.

28. Dong wang, Qiongzhen Liu, Yuedan Wang, Mufang Li, Ke Liu, Jiahui Chen and Xing Qing : "Reinforcement of Polyethylene Terephthalate via Addithon of Carbon - Based Materials", Copyright (C) Elsevier Inc., 2015.

29. X. Wang, J. Wang, W. Zhao, L. Zhang, X. Zhong, R. Li, and J. Ma: "Synthesis and characterization of thermo tropicliquid crystalline polyester/multi-walled carbon nanotube nanocomposites "Applied Surface Science, vol. 256, pp.1739-1743, 2010.

30. H. Badran, MoK. Hassan, W. Y. Ali: "Tribological Behaviour of Epoxy Reinforced with Carbon Nanotubes and Filled by vegetables oils," El-Minia University, 6 El Minia, Egypt, E-Mail-Wahyos@ Hotmail.com, 2017.

31. A.El-Syed M. Hassan, Alaa I Eid , M. Elsheikh and W.Y.Ali: "Effect of Graphine Nanoplatelets and Paraffin Oil Addition on the Mechanical and Tribological Properties of Low-Density Polyethylene Nanocomposites", (C) King Fahd University of Petroleum \& Minera. Arab- J Sci Eng. 43: pp 1435-1443, 2018.

32. Wu J. B.,Zeng X. S., Luo L., Yuan Q. H.: Friction and wear properties of Carbon Nanotubes/AZ91 composites. Mater. Mech. Eng.; 39:101-105, 2015

33. Kim I.Y., Lee J.H., Lee G.S., Baik S.H., Kim Y.J., Lee Y.Z.: Friction and wear characteristics of the carbon nanotube-aluminum composites with different manufacturing conditions. Wear. 2009; 267:593-598. vol: 10.1016/j. wear..12.096. (CrossRef), 2008.

34. B. Arash, Q wang and V. K. Varadon: "Mechanical Properties of Carbon nanotube Polymer Composites", Scientific Reports, October 2014. 